\title{
MANAGEMENT OF ACUTE STROKE DUE TO TANDEM OCCLUSIONS WITH CAROTID STENTING AND INTRACRANEAL THROMBECTOMY.
}

A. Boix Moreno ${ }^{1}$, T. Mateos Salas ${ }^{1}$, C. Jimenez Martinez ${ }^{1}$, I. Legarda Ramirez ${ }^{1}$, S. Miralbes Celma², R. Bermejo Garces², A. Moreno Rojas ${ }^{1}$, M.

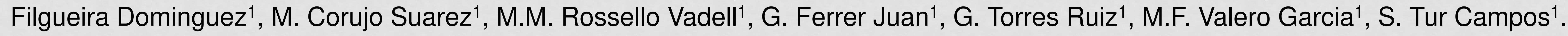

${ }^{1}$ Hospital Universitario Son Espases, Neurology, Palma de mallorca, Spain. ${ }^{2}$ Hospital Universitario Son Espases, Radiology, Palma de mallorca, Spain.

\section{BACKGROUND AND AIMS:}

The management of tandem occlusion represents a major challenge in patients with acute ischemic stroke (AIS), we want to present our results in patients with AIS due to tandem occlusions treated with Mechanical Thrombectomy (TM) and acute carotid stenting.

\section{METHOD:}

We performed a retrospective review of our prospective maintained, singleinstitution database between December 2014 and December 2017. We analyzed demographic, radiological, and clinical outcome data for patients who underwent endovascular treatment for tandem occlusion with acute carotid stenting. A modified Rankin Scale score (mRs) 2 at 90 days was defined as a favorable clinical outcome.

\begin{tabular}{|c|c|}
\hline $\mathrm{N}$ total & 34 \\
\hline Age, yr, mean & 61.75 \\
\hline Men & $29(85 \%)$ \\
\hline \multicolumn{2}{|l|}{ MEDICAL HISTORY } \\
\hline Hypertension & $18(37,4 \%)$ \\
\hline Diabetes & $6(17,6 \%)$ \\
\hline Hypercholesterolemia & $16(29,6 \%)$ \\
\hline Atrial Fibrillation & $1(2,9 \%)$ \\
\hline Current smoking & $18(35,5 \%)$ \\
\hline Antiplatelets & $13(38,2 \%)$ \\
\hline Anticoagulation & none \\
\hline Statins & $13(38,2 \%)$ \\
\hline Admission NIHSS, mean (SD) & $16(5.8)$ \\
\hline 24h NIHSS & $8(6.5)$ \\
\hline Discharge NIHSS & $5(4.9)$ \\
\hline \multicolumn{2}{|l|}{ TREATMENT } \\
\hline Prior IV thrombolysis & $23(68 \%)$ \\
\hline General anesthesia & $34(100 \%)$ \\
\hline Pneumonia & $3(8.8 \%)$ \\
\hline Mean procedure time, min. (IQR) & $64.5(45.25-90)$ \\
\hline Successful reperfusion (mTICl 2b-3) & $33(97.1 \%)$ \\
\hline $\mathrm{mTICl} 0$ & $1(2.9 \%)$ \\
\hline $\mathrm{SICH}$ & $2(5.7 \%)$ \\
\hline \multicolumn{2}{|l|}{ OUTCOME } \\
\hline In-hospital mortality & $3(8.8 \%)$ \\
\hline 90-day good Outcome (mRS 0-2) & $17(65.38 \%) n: 26$ \\
\hline
\end{tabular}

\section{RESULTS:}

Thirty- four patients were identified for inclusion in the study, the average age of these patients was 61.7 years; the mean National Institutes of Health Stroke Scale score (NIHSS) at presentation was 16. Twenty three patients received intravenous thrombolysis before undergoing endovascular treatment $(68 \%)$. The stroke etiology was mainly atherothrombotic $(77 \%)$. All our endovascular treatments were completed with general anesthesia. The median time from groin to revascularization was 64.5 minutes (IQR 45.25-90). Successful reperfusion rate (modified Thrombolysis In Cerebral Infarction score $\geq 2 b$ ) was obtained in all but one of our patients $(97 \%)$.

The rate of symptomatic intracranial hemorrhage $(\mathrm{SICH})$ was $6 \%$. The mean NIHSS score were 8 points at $24 \mathrm{~h}$ postprocedure and 4.5 points at discharge*. Good outcome was achieved in $65.38 \%$ of the patients*.

\section{CONCLUSION:}

The management of tandem occlusions with acute carotid stenting in our center, involves good outcome and a low rate of $\mathrm{sICH}$ in accordance to the frequency found in similar case series ${ }^{1}$.

\section{REFERENCES}

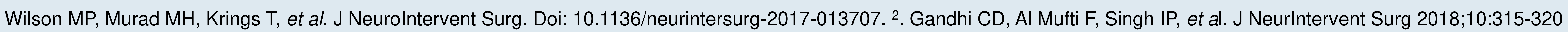

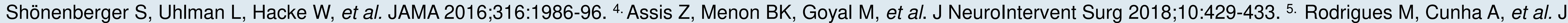
Neurol Sci. 2018 Apr 15;387:196-198. ${ }^{6}$. Ilyas, Adeel et al. World Neurosurgery, Volume 112 , e355 - e367 